\title{
A comparative study on selective properties of Kraft lignin- natural rubber composites containing different plasticizers
}

\author{
Janusz Datta ${ }^{1}$ P Paulina Parcheta ${ }^{1}$
}

Received: 17 December 2016 / Accepted: 22 May 2017 / Published online: 27 May 2017

(c) The Author(s) 2017. This article is an open access publication

\begin{abstract}
Effect of plasticizer type on the kraft lignin-natural rubber composite microstructure and selected properties was determined. The composites were prepared with addition of a commonly used naphthenic oil plasticizer to study the decomposition product of polyurethane (glycerolysate) and its characteristics. Kraft lignin powder was incorporated into the natural rubber matrix in amounts of 10 and 40 parts per 100 parts of natural rubber (phr). The reference samples were prepared without any lignin present. The chemical interaction between the filler particles and natural rubber macromolecules was analyzed by Fourier transform infrared spectroscopy (FTIR) and the adhesion was characterized by scanning electron microscopy (SEM). The results of the adhesion measurements confirmed poor distribution of lignin particles into the natural rubber matrix with increasing filler content. Optimal lignin content in the composites was $10 \mathrm{phr}$ in the case of both plasticizers. Moreover, the results of FTIR verified the formation of non-covalent bonds and the need for modification of the filler to enhance the reinforcing effect in the natural rubber matrix. Dynamic mechanical analysis (DMA) and mechanical measurements proved that the specimen containing $10 \mathrm{phr}$ of lignin with the use of glycerolysate as plasticizer displayed the highest mechanical performance. It was demonstrated that glycerolysate and naphthenic oil as plasticizing agents showed similar effect on the thermal properties of the prepared composites. Also, the measured
\end{abstract}

Janusz Datta

janusz.datta@pg.gda.pl

1 Department of Polymer Technology, Faculty of Chemistry, Gdańsk University of Technology, G. Narutowicza St. 11/12, 80-233 Gdańsk, Poland mechanical properties, such as tensile strength, hardness, resilience, and abrasiveness confirmed these findings.

Keywords Kraft lignin - Natural rubber composites · Glycerolysate $\cdot$ Scanning electron microscopy $\cdot$ Thermal properties

\section{Introduction}

Growing interest in the field of biorenewables' utilization in chemistry, chemical technology, and materials science has shifted polymer science study increasingly toward such trend. Preparation of the composites from natural substances and those derived from renewable and biodegradable sources has been widely studied. These ecological proceedings emerge from the outcome of exhausting resources of fossil feedstocks such as a coal, natural gas, and crude oil, which prompt the necessity to reduce utilization of petrochemicals and other non-renewable sources.

Currently, lignin is one of the most abundant natural polymers, after cellulose, which occurs on a large scale. Approximately 50 million tons lignin are annually generated by the paper and pulp industries. So far, the biggest amount of lignin by-product has been used such industries as a fuel for energy production. Today, it is important to find other more functional uses of this valuable by-product. There are three types of commercially available lignin: kraft, soda, and lignosulfonates. Determining these types of lignin is associated with most industrial processes in wood delignification: kraft, soda, and sulfite, respectively. Effectively the recovered kraft lignin has low sulfur content, ashes, and residual sugars. Its main application is the production of water-soluble sulfonated derivatives with a purity superior to that of lignosulphonates. They are used as 
dispersants and emulsifiers in a wide range of applications such as dye dispersants, agrochemical dispersants, battery expanders, and conductive polymers. Non-modified kraft lignins are used to a less extent, mainly not only as asphalt emulsifiers, but also as anti-oxidants, carriers, adsorbents, and UV screens.

Lignin is a highly branched bio-macromolecule composed of units such as para-coumaryl alcohol, coniferyl alcohol, and sinapyl alcohol [1]. These molecules are linked together by different bond types such as $\alpha-O-4, \beta-O-4$, $\beta-3, \beta-5, \beta-\beta$, etc. [2]. Due to these bond types, lignin has many significant functional groups such as hydroxyl, methoxyl, carboxyl, and carbonyl groups, which are present in different proportions depending on the type of lignin [3, 4]. The lignin used as filler gives the special functional properties like oxidation resistance, stabilization, reinforcement, biodegradability, anti-fungal and antibiotic activity, or UV-absorption resistance in the polymer composites. The occurrence of the above-mentioned groups makes lignin polar, and thereby incompatible with non-polar polymers, including natural rubber. However, in the case of the rubber-based composites, the reinforcing effect depends on the interfacial bonding between lignin and rubber matrix and also on the size of the filler particles. In the natural rubber composites, unmodified lignin does not have the reinforcing effect [5] through the intermolecular hydrogen bonding formation between the lignin particles. Thereby, the filler is not dispersed well and it does not act like a reinforcing agent [3]. Despite the fact that the lignin can form agglomerates when appearing in a large amount, it has the great potential to stabilize a polymer composite in its preparation procedure. Moreover, it can be used as cost-reductive filler, emulsifier, dispersant or other additives in polymers $[6,7]$. Commonly available lignin powder is in the form of microand nano-particles, as fibers (lignin-based carbon fiber) [8] or flakes. Lignin, compared with carbon black or silica, discloses non-conducting properties, less density, and lighter pigmentation in the rubber composites. Thereby, it makes possible to prepare rubber-based materials with light color [3]. Moreover, this natural product has also other advantages such as low cost, renewable and biodegradable character, reactive surface, and the possibility of power generation during combustion [9].

The second important activity, which leads to the waste production reduction, is to find more possible applications of the polymer decomposition product in the polymer matrix. One of the most developing branches of polymers is polyurethanes. These materials are in the fifth place with ca. 7\% global polymer usage, ranking as the most used polymers in the world. Due to this, the scientists working on polyurethanes consider to lower the waste reduction related to these polymers, which constitute ca. $6 \%$ of all plastic waste [10]. Increasing interest in the field of polyurethane waste recycling methods has attracted a growing interest in the possibility of the polyurethane decomposition product application in the polymer composites. It is also desirable that the received new bio-based materials containing the thermo-chemical recycling product of polyurethanes should possess improved functional properties.

There are two basic methods of polyurethane chemical recycling. Glycerolysate is the thermo-chemical decomposition product of polyurethane obtained with the use of glycerine as a depolymerizing agent during glycerolysis [10]. The second method involves polyurethane depolymerization with the use of glycol as a decomposition prime mover and the process is named glycolysis [11, 12]. The most developed polyurethane recycling methods are related to the decomposition of the flexible foams due to their extensive global usage and high volume of wastes. Currently, scientists in the field of polymer science are working on the possibility of utilization of this product as a raw material for the polymer synthesis. Until now, these products were most frequently used for new polyurethane materials' synthesis in the form of foams [13] or elastomers $[14,15]$, in which polyols are partially or entirely replaced by the product of the chemical recycling, or as the components for other applications [16, 17]. This experimental set up was an exemplification of the new application of the glycerolysate-product of the polyurethane's chemical decomposition.

In recent years, much attention has been devoted to the possibility of the petrochemical-based plasticizers replacement by the bio-based materials. Due to the competitive mechanical properties offered by biopolymers used as biodegradable plasticizers, these materials have been considered as the most promising substitute for petrochemicalbased plasticizers [18]. Alexander and co-workers [19] employed cardanol, the primary ingredient of cashew nut shell liquid, as a plasticizer in the carbon black/natural rubber composites. The results of the mechanical properties, cure time, and aging behavior confirmed the similar or even better properties compared to aromatic oil-based composites. Mohapatra et al. [20] also confirmed the plasticization effect of the cardanol incorporation into natural rubber matrix. Silva et al. [21] synthesized the natural plasticizer with the use of esterification reaction between rice fatty acids and glycols. The obtained plasticizer was successfully incorporated into natural rubber matrix. Mechanical and thermal test results, for example increase in the elongation-at-break and the lack of significant changes in the thermal behavior measured by TGA, in comparison with composites without plasticizer, showed promising application for a novel natural plasticizing agent.

The main aim of this research was to determine the effect of plasticizer type on the kraft lignin-natural rubber composites microstructure and selected properties. Novel 
elastic composites were prepared with the use of glycerolysate as a plasticizing agent. Moreover, kraft lignin, a byproduct in paper and pulp industry, was used as various filler contents. Justification of the kraft lignin choosing as natural filler was determined due to its easy accessibility, wide range of utilization, and good impact on the products' final properties [1]. Moreover, the filler content was chosen based on the results of our previous work connected with the lignin/natural rubber composites [22]. In comparison with the composites containing commonly used naphthenic oil as a plasticizer, the new composite was prepared to verify the proposed solution associated with the use of the polyurethane decomposition product. The results of the structure, morphology, selected thermal and mechanical properties of these composites allowed to confirm the possibility to use glycerolysate as a plasticizing agent in the natural rubber matrix.

\section{Experimental}

\section{Materials}

The kraft lignin powder-REAX 910 (density: $0.55 \mathrm{~g} / \mathrm{cm}^{3}$ ), used in this study as a filler, was obtained from MeadWestvaco Corporation, Specialty Chemical Division, South Carolina, USA. Lignin was dried prior to use at $100{ }^{\circ} \mathrm{C}$ for $12 \mathrm{~h}$ in air. Natural rubber (density: $0.92 \mathrm{~g} / \mathrm{cm}^{3}$, weight average molecular weight, $M_{\mathrm{w}}: 800,000 \mathrm{~g} / \mathrm{mol}$ ) and sulfur (density: $1.8 \mathrm{~g} / \mathrm{cm}^{3}$, molecular weight: $32.1 \mathrm{~g} / \mathrm{mol}$ ) were purchased from Torimex Chemicals Ltd Sp. z o. o., Konstantynów Łódzki, Poland. Stearic acid (density: $0.9 \mathrm{~g} / \mathrm{cm}^{3}$, molecular weight: $284.5 \mathrm{~g} / \mathrm{mol}$ ), zinc oxide (density: $5.6 \mathrm{~g} /$ $\mathrm{cm}^{3}$, molecular weight: $81.4 \mathrm{~g} / \mathrm{mol}$ ), stabilizer AR (phenyl$\beta$-naphthylamine, density: $1.16 \mathrm{~g} / \mathrm{cm}^{3}$, molecular weight: $219.3 \mathrm{~g} / \mathrm{mol}$ ), and accelerator $T$ (tetramethylthiuram disulfide, density: $1.5 \mathrm{~g} / \mathrm{cm}^{3}$, molecular weight: $240 \mathrm{~g} /$ mol) were purchased from Brenntag Polska Sp. z o. o., Kędzierzyn-Koźle, Poland. The glycerolysate (number average molecular weight: $902.4 \mathrm{~g} / \mathrm{mol}$, hydroxyl number: $186.5 \mathrm{mg} \mathrm{KOH} / \mathrm{g}$ ) was produced in the Department of Polymer Technology at Gdańsk University of Technology and used as a plasticizer. The naphthenic oil (Nytex 810, Nynas, Poland) was the second plasticizer.

\section{Sample preparation}

Natural rubber (NR) composites containing one of the two types of plasticizers were prepared in accordance with the quantities shown in Table 1. NR prior to mixing was annealed to improve mastication process. Then rubber mix was prepared. Lignin was added in two different amounts, i.e. 10 and 40 parts per 100 parts of natural rubber (phr). Reference samples without lignin content were also prepared. Both plasticizers were added in the same amount and the choice of plasticizer value was made in accordance with the literature [3].

The ingredients were mixed by Buzuluk open two-roll mill [23]. The friction ratio of rolls was 1:1.07 and the prepared mixes were vulcanized at the temperature of $146{ }^{\circ} \mathrm{C}$ for $10 \mathrm{~min}$ (an appropriate vulcanization time) by using a ZUP Nysa hydraulic press (approximately under pressure of $5 \mathrm{MPa}$ ). Chosen vulcanization time applied by our research group is similar to that presented in the literature $[24,25]$.

\section{Fourier transform infrared spectroscopy (FTIR)}

The interaction between lignin particles and natural rubber macromolecules was characterized by Fourier transform infrared spectra using ATR (attenuated total reflectance) technique. The measurements were carried out
Table 1 Amounts of the ingredients for preparation of lignin-rubber composites

\begin{tabular}{lllllll}
\hline Components & \multicolumn{2}{l}{ Quantities of ingredients (phr) } \\
\cline { 2 - 6 } & WLR0 & \multicolumn{7}{l}{ WLR10 } & \multicolumn{2}{l}{ WLR40 } \\
\hline Plasticizer type $^{\mathrm{a}}$ & $\mathrm{G}$ & $\mathrm{M}$ & $\mathrm{G}$ & $\mathrm{M}$ & $\mathrm{G}$ & $\mathrm{M}$ \\
Natural rubber & 100 & 100 & 100 & 100 & 100 & 100 \\
Stearic acid & 3 & 3 & 3 & 3 & 3 & 3 \\
Zinc oxide & 5 & 5 & 5 & 5 & 5 & 5 \\
Stabilizer AR & 1.5 & 1.5 & 1.5 & 1.5 & 1.5 & 1.5 \\
Accelerator T & 0.5 & 0.5 & 0.5 & 0.5 & 0.5 & 0.5 \\
Naphthenic oil (M) & - & 2 & - & 2 & - & 2 \\
Glycerolysate (G) & 2 & - & 2 & - & 2 & - \\
Kraft lignin & - & - & 10 & 10 & 40 & 40 \\
Sulfur & 3 & 3 & 3 & 3 & 3 & 3 \\
\hline
\end{tabular}

a All the ingredients are characterized in the text 
using spectrophotometer Nicolet 8700 FTIR produced by Thermo Electron Corporation, USA. Measurements were taken with 64 scans in the wavenumber range from 4500 to $500 \mathrm{~cm}^{-1}$. The resolution was $4 \mathrm{~cm}^{-1}$.

\section{Scanning electron microscopy (SEM)}

Characterization of the cross-section morphology of prepared lignin-rubber composites was performed by scanning electron microscopy (SEM) with the use of a Phenom G2 PRO scanning electron microscope (Phenom-World Corporation, Netherlands) at an accelerating voltage of $\sim 5 \mathrm{kV}$. The cross-sections of all the rubber composites were prepared by a knife.

\section{Thermogravimetric analysis (TGA)}

The thermal stability of the bio-based composites was characterized by thermogravimetric analysis. Measurements were carried out under nitrogen atmosphere with the use of a NETZSCH TG 209F3 analyzer (Netzsch, Germany). Samples with a weight of $\sim 8 \mathrm{mg}$ were analyzed in the temperature range of $35-600{ }^{\circ} \mathrm{C}$ at a heating rate of $20{ }^{\circ} \mathrm{C} /$ min. The thermogravimetric (TGA) and differential thermogravimetric (DTG) curves were plotted based on the obtained results.

\section{Dynamic mechanical analysis (DMA)}

The dynamic mechanical thermal analysis of the kraft lignin-natural rubber composites was carried out with the use of a DMA Q800 analyzer (TA Instruments, USA). The measurements were realized in accordance with the ISO 6721-1. The values of storage modulus and tangent delta (damping factor) were obtained in the temperature range of $100-150{ }^{\circ} \mathrm{C}$ with a heating rate of $4{ }^{\circ} \mathrm{C} / \mathrm{min}$, under the air atmosphere and $1 \mathrm{~Hz}$ frequency. Orthogonally shaped specimens with dimensions $30 \times 5 \times 2 \mathrm{~mm}$ were analyzed. The single torsion mode was used as mechanical stress during measurements. In order to obtain the mechanical characteristics, the variations of storage modulus $\left(\mathrm{E}^{\prime}\right)$ versus temperature and $\tan \delta$ versus temperature were plotted. DMA tests allowed verifying the influence of the lignin content and the plasticizer type on the composites thermo-mechanical properties. Furthermore, these measurements allowed the determination of the glass transition temperature of the prepared kraft lignin-natural rubber composites, which was assumed as the transition in the $\tan \delta$ curves. The storage modulus $\left(\mathrm{E}^{\prime}\right)$ is provided to give information about the material stiffness and the stored energy, while loss factor $(\tan \delta)$ measures the degree of molecular motion [26].

\section{Mechanical properties}

The static tensile test of lignin-rubber composites was carried out with the use of a Zwick/Roell Z020 universal testing machine (Zwick, Germany). The results of the tensile strength, elongation-at-break, and permanent elongation after the break were determined according to the standard ISO 37. The crosshead speed was $300 \mathrm{~mm} / \mathrm{min}$ with using a 20-kN load cell. The dumbbell-shaped samples of all composites were tested. The obtained results are reported as an average value calculated from three samples.

The hardness was measured with the use of a Shore type A Durometer (Zwick/Roell electronic hardness testing machine) (Zwick, Germany). The measurements were carried out according to the standard ISO 868. The circularshaped specimens with $6 \mathrm{~mm}$ thickness were tested. The study consisted of ten measurements and average hardness calculation.

The rebound resilience test was carried out using the Schob machine. The circular-shaped specimens with $6 \mathrm{~mm}$ thickness were tested in accordance with the ISO 4662. The results are the average of ten independent measurements.

The density of the prepared composites was determined using an electronic analytical balance equipped with a kit for measuring the solids' density. The tests were realized according to the standard ISO 2781. A single measurement consisted in measuring sample's weight in air, then in methanol with known density $\left(0.790 \mathrm{~g} / \mathrm{cm}^{3}\right)$ at $\sim 23^{\circ} \mathrm{C}$. The mean values calculated from three independent measurements are reported for all the composites.

The abrasiveness was determined according to the ISO 4649. The abrasion resistance for selected samples was investigated using the Schopper-Schlobbach instrument. The samples were circular shapes with $17 \mathrm{~mm}$ diameter. The tests were performed for three samples of each material. The abrasiveness $V\left(\mathrm{~cm}^{3}\right)$ was calculated with the use of Eq. (1):

$V=\frac{\left(m_{1}-m_{2}\right) \times 0.2}{\rho \times \Delta m_{w}}$,

where $m_{1}(\mathrm{~g})$ and $m_{2}(\mathrm{~g})$ are the mean mass of the sample before and after the test, respectively, $0.2(\mathrm{~g})$ - the theoretical loss in weight of the reference mixture, $\rho\left(\mathrm{g} / \mathrm{cm}^{3}\right)$ - the tested sample density, $\Delta m_{\mathrm{w}}(\mathrm{g})$ - the average weight loss of the reference mixture whose abrasiveness was known (accepted the value of $0.1095 \mathrm{~g}$ ). The abrasion resistance was defined as a volume loss $\left(\mathrm{cm}^{3}\right)$.

\section{Equilibrium swelling studies}

The equilibrium swelling method was used to determine the swelling index, the volume fraction of rubber network, the molecular weight of the polymer between the 
crosslink points, and crosslink density. The tests were carried out in accordance with that presented in literature $[24,27,28]$. The rectangular-shaped samples with an average size of $15 \times 15 \times 2 \mathrm{~mm}$, were immersed in pure toluene (purchased from $\mathrm{POCH}$, Gliwice, Poland) at room temperature for 7 days $(168 \mathrm{~h})$. In this period of time, the samples were removed from immersion liquid, dried by paper, weighed, and again placed in toluene. After obtaining equilibrium swelling state, the samples were dried in the air for 7 days and after this time they were subjected to annealing at the temperature of $80{ }^{\circ} \mathrm{C}$ for $3 \mathrm{~h}[27,29]$. The swelling ratio was calculated from Eq. (2):

$\mathrm{SR}=\frac{m_{1}-m_{0}}{m_{0}} \times 100 \%$,

where $m_{0}(\mathrm{~g})$ and $m_{1}(\mathrm{~g})$ are the mean weight of the tested samples before and after swelling in immersion liquid, respectively. Thereafter, the rubber volume fraction $V_{\mathrm{fr}}$ was calculated using Eq. (3):

$V_{\mathrm{fr}}=\frac{V_{\mathrm{r}}}{V_{\mathrm{r}}+V_{\mathrm{s}}}=\frac{\frac{m_{\mathrm{r}}}{\rho_{\mathrm{rr}}}}{\frac{m_{\mathrm{r}} m_{\mathrm{s}}}{\rho_{\mathrm{rr}} \rho_{\mathrm{s}}}}$,

where $V_{\mathrm{r}}\left(\mathrm{cm}^{3}\right)$ and $V_{\mathrm{s}}\left(\mathrm{cm}^{3}\right)$ are the mean volumes of the rubber and solvent in the swollen sample, respectively, $m_{\mathrm{r}}$ (g) and $m_{\mathrm{s}}(\mathrm{g})$ denote the mean weights of the rubber and solvent in the tested samples before and after swelling in the immersion liquid, respectively, and $\rho_{\text {rr }}\left(\mathrm{g} / \mathrm{cm}^{3}\right)$ and $\rho_{\mathrm{s}}\left(\mathrm{g} / \mathrm{cm}^{3}\right)$ - the rubber density $\left(0.9125 \mathrm{~g} / \mathrm{cm}^{3}\right.$ for natural rubber) and solvent density $\left(0.867 \mathrm{~g} / \mathrm{cm}^{3}\right.$ for toluene), respectively. The rubber volume fraction $\left(V_{\mathrm{fr}}\right)$ gives the opportunity to calculate the average molecular weight of the polymer between the crosslink points, $M_{\mathrm{c}}(\mathrm{g} / \mathrm{mol})$, using the Flory-Rehner theory, presented in Eq. (4):

$M_{\mathrm{c}}=\frac{-\rho_{\mathrm{r}} \times V_{\mathrm{s}} \times\left(V_{\mathrm{fr}}^{\frac{1}{3}}-\frac{1}{2} V\right)_{\mathrm{fr}}}{\ln \left(1-V_{\mathrm{fr}}\right)+V_{\mathrm{fr}}+\left(\chi \times V_{\mathrm{fr}}^{2}\right)}$,

where $\rho_{\mathrm{r}}\left(\mathrm{g} / \mathrm{cm}^{3}\right)$ stands for the density of lignin-natural rubber composites, $V_{\mathrm{s}}$-the molar volume of the solvent (for toluene: $106.52 \mathrm{~cm}^{3} / \mathrm{mol}$ ), $\chi$-the Huggins parameter, defining the interaction between polymer and solvent ( 0.38 for natural rubber-toluene). The crosslink density $v$ $\left(\mathrm{mol} / \mathrm{cm}^{3}\right)$ was determined using Eq. (5):

$v=\frac{\rho_{\mathrm{r}}}{M_{\mathrm{c}}}$,

where $\rho_{\mathrm{r}}\left(\mathrm{g} / \mathrm{cm}^{3}\right)$ stands for the polymer (lignin-natural rubber composite) density and $M_{C}(\mathrm{~g} / \mathrm{mol})$ is the average molecular weight of the polymer.

\section{Results and discussion}

\section{Fourier transform infrared spectroscopy (FTIR)}

The chemical structures of the pure components (kraft lignin, glycerolysate, naphthenic oil, natural rubber, and prepared composites) were studied by FTIR analysis. Figure 1a and $\mathrm{b}$ illustrates the obtained FTIR spectra in the wavenumber range of $4500-500 \mathrm{~cm}^{-1}$. The minor differences between the studied composite materials are especially related to the intensity of the observed characteristic vibrations. The wide peak presented in all the spectra, in the wavenumber range of $3570-3170 \mathrm{~cm}^{-1}$, is related to the hydroxyl groups stretching vibrations [30]. The most intensive peak of $-\mathrm{OH}$ groups is visible at the spectra of kraft lignin and glycerolysate. The strong

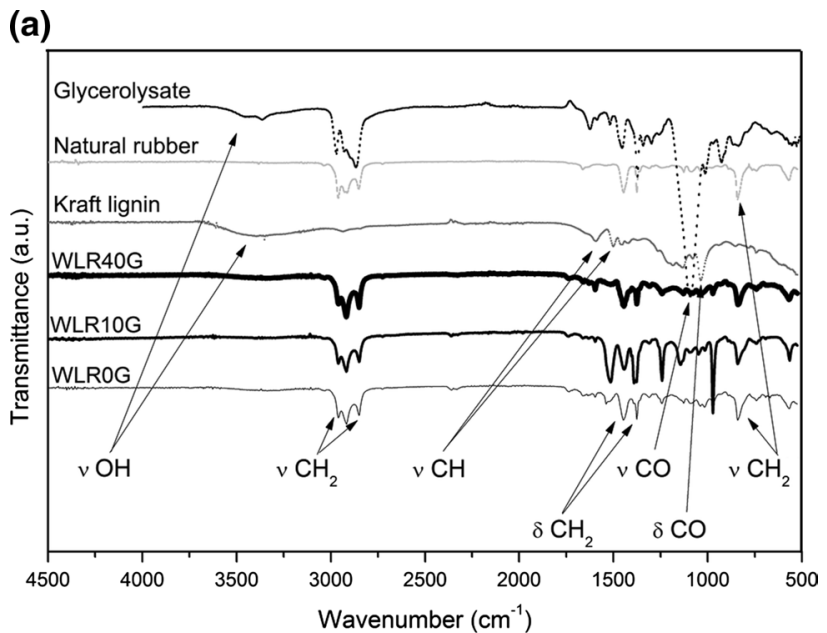

(b)

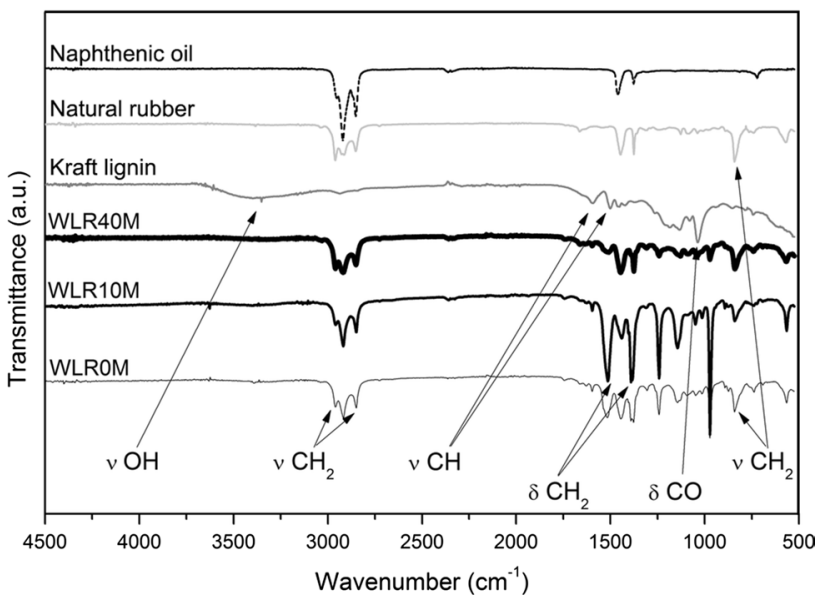

Fig. 1 a FTIR spectra of the composites with the use of glycerolysate as plasticizer, pure glycerolysate, natural rubber, and lignin; and b FTIR spectra of the samples with the use of naphthenic oil, pure naphthenic oil, natural rubber, and lignin 
peaks at 2960,2917 , and $2850 \mathrm{~cm}^{-1}$ belong to the methylene groups $-\mathrm{CH}_{2}$ symmetric and asymmetric stretching vibrations $[29,31]$ primarily from natural rubber macromolecules but also from glycerolysate and lignin particles. In the kraft lignin curves in Fig. 1a and b, the small peaks at 1600 and $1500 \mathrm{~cm}^{-1}$ belong to the symmetric and asymmetric stretching vibrations of methyl groups $-\mathrm{CH}$ derived from aromatic skeletal vibration $[4,32]$. The intensive bands at 1450 and $1377 \mathrm{~cm}^{-1}$ that appeared in the spectra of the pure glycerolysate, naphthenic oil, natural rubber, and composites, are attributed to deformation vibrations of methylene groups $-\mathrm{CH}_{2}$ [33]. The most intensive peak for glycerolysate at $1096 \mathrm{~cm}^{-1}$ and peak for lignin spectrum at $1030 \mathrm{~cm}^{-1}$ are connected with the stretching vibration $-\mathrm{C}-\mathrm{O}$ ether groups and with the deformation vibrations of $-\mathrm{C}-\mathrm{O}$ methoxyl groups, respectively. The peak near the wavenumber $839 \mathrm{~cm}^{-1}$ is related to the variations of $-\mathrm{CH}_{2}$ groups in rubber chains [34].

From this figure, it can be seen that the intensities of peaks belonging to the corresponding functional groups are not increased with a lignin growing amount in the composites. The analysis indicates that it was caused by the formation of the lignin agglomerates. These agglomerates were formed with the increase in lignin content, which resulted in the disrupted spectrum.

The interaction between rubber and filler represents one of the most studied matters of concern in the rubber science and technology. It is well-known that the rubber can interact with the filler surface through chemisorption, physical adsorption and/or crosslinking. The interaction between natural rubber macromolecules and kraft lignin particlescan be explained based on the obtained FTIR spectra. Pillai and Renneckar [35] and Yang and co-workers [36] explained the interaction between lignin units and poly(diallyldimethylammonium chloride) (PDADMAC) chain using FTIR spectra. They also indicated the similarity in the chain skeletons of NR and PDADMAC. Based on these results, it was concluded that the lignin interacts in a similar way with the rubber. As shown in Fig. 1, the peaks at 1596 and $1500 \mathrm{~cm}^{-1}$, for the kraft lignin spectrum, shift to 1600 and $1515 \mathrm{~cm}^{-1}$, respectively, in the composites' spectrum. These small shifts indicate a non-covalent interaction between the NR chain and kraft lignin particles [3, 35, 36].

Phakkeeree and co-workers [37] also investigated the interaction between natural rubber and lignin in the composites by using a high-ammonia natural rubber latex and the lignin powder which was dissolved in $0.1 \mathrm{M} \mathrm{NaOH}$ aqueous solution $(30 \mathrm{w} / \mathrm{v} \%)$ before application. The researchers confirmed the lignin aggregation around the rubber chains which led to smaller contact area between filler and rubber. Nevertheless, the ionic sites in lignin derived from $\mathrm{NaOH}$ solution increased the filler interaction with natural rubber. In our research, the lignin powder was added without any modification, which confirmed the noncovalent interaction.

\section{Scanning electron microscopy (SEM)}

Scanning electron microscopy was used to investigate the cross-sections of the prepared composites. This investigation allowed characterizing the lignin dispersion in the composites and interaction between the natural rubber chain and the kraft lignin powder. In Fig. 2a and b, there are shown the SEM micrographs of the reference samples, where some impurities are visible. The pictures 2 (c-f) illustrate the filler agglomerate formation with the increasing amount of lignin in the composites. These findings indicate the hydrogen bond formation between the filler particles. This concentration of lignin particles revealed the similar size in the case of both plasticizers. Agglomerates have an irregular shape with the average dimension from several to several tens of micrometers. Specimens with the highest amount of lignin formed the biggest agglomerates. Moreover, the kraft lignin-natural rubber composites, prepared by using naphthenic oil as a plasticizer, revealed agglomerates with bigger diameters than the composites with glycerolysate (Fig. 2e, f). This observation can be confirmed by the glycerolysate used in the composite preparation. The synthesis of this plasticizer is mostly catalyzed with the use of basic catalysts and consequently reveals more alkaline character than naphthenic oil. The glycerolysate can participate in the composite reaction mechanism and gently improve the lignin powder dispersion. Similar results were obtained by Phakkeeree et al. [37]. The voids seen in the images (c-f) are related to the loss of lignin particles during the cross-section preparation. The analysis indicates the lack of interfacial interaction between the lignin particles and the natural rubber matrix. This conclusion is supported also by the cavity observed around the filler particles in Fig. 2. Asis well known, the size of the filler has also an impact on the reinforcing behavior of the resulting composite [38]. Consequently, big agglomerates of the lignin and presence of the cavity decrease the possibility to bear the external stress by the composite. The smaller particles of filler with good dispersion in the composites enable those compositesto bear the higher stress. The results of the scanning electron microscopy indicate poor lignin molecules incorporated into the rubber macromolecules. Moreover, it has been proved that the lignin modification is necessary to achieve better filler dispersion in the natural rubber matrix which is also related to the reinforcing effect in the composites [3].

Noteworthy is the fact that the observed lignin agglomerates in the glycerolysate-based composites did not increase in value by the growing lignin content, which is seen in the 
Fig. 2 SEM images of: $\mathbf{a}, \mathbf{b}$ reference samples; $\mathbf{c}, \mathbf{d}$ samples with 10 phr lignin; and e, f samples with $40 \mathrm{phr}$ lignin, with the use of glycerolysate $(\mathbf{a}, \mathbf{c}, \mathbf{e})$ and naphthenic oil $(\mathbf{b}, \mathbf{d}, \mathbf{f})$ as plasticizers
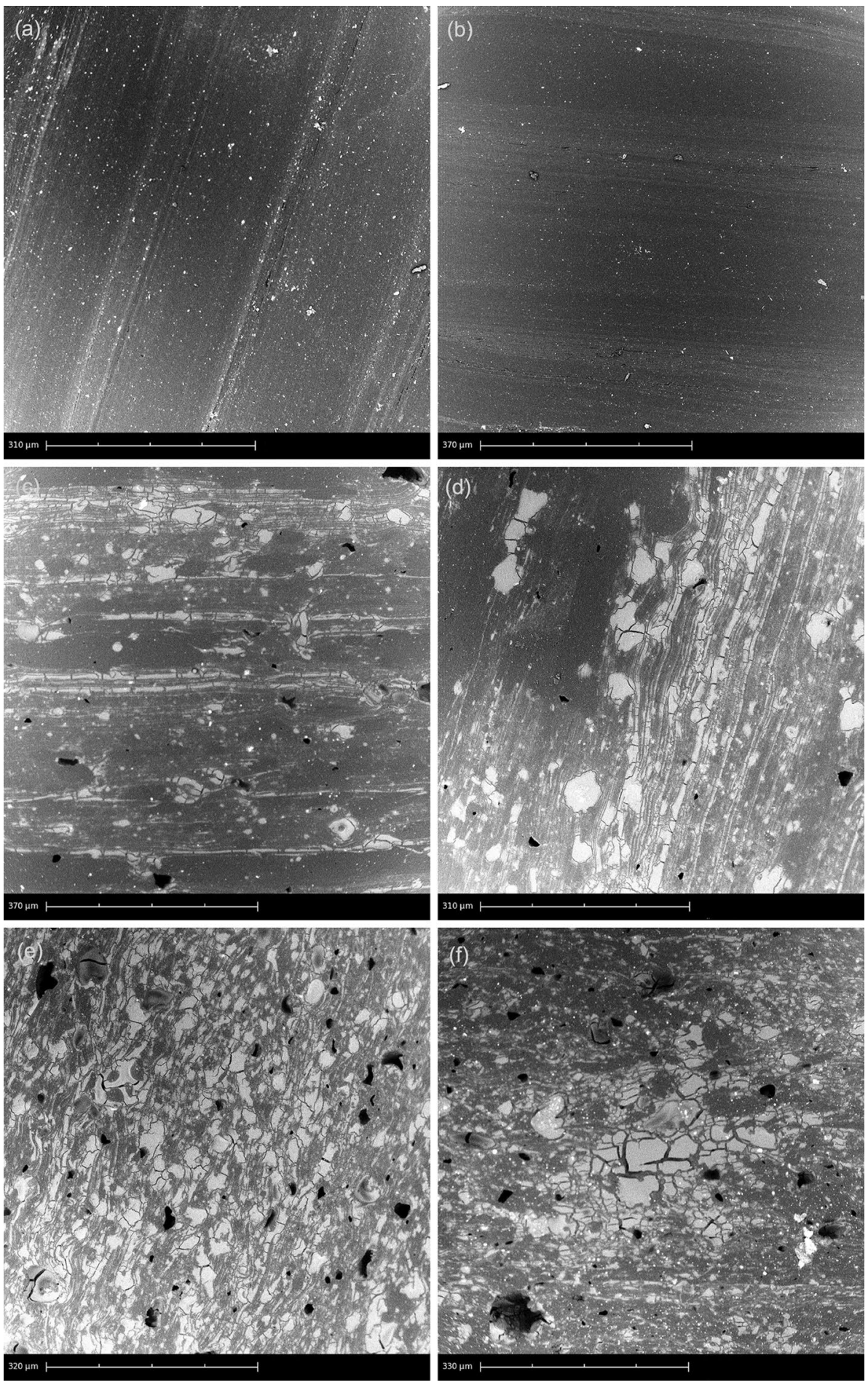

naphthenic oil-based materials. However, the number of lignin agglomerates in the glycerolysate-based composites has increased. This can be explained by the glycerolysate content. Despite the lignin polydispersity, the novel plasticizer suppresses the accumulation of lignin particles into larger agglomerates.

\section{Thermogravimetric analysis (TGA)}

The thermal stability of the kraft lignin-natural rubber composite samples without lignin content, pure lignin, and used plasticizers was investigated with the use of thermogravimetric analysis. The measurements helped produce 

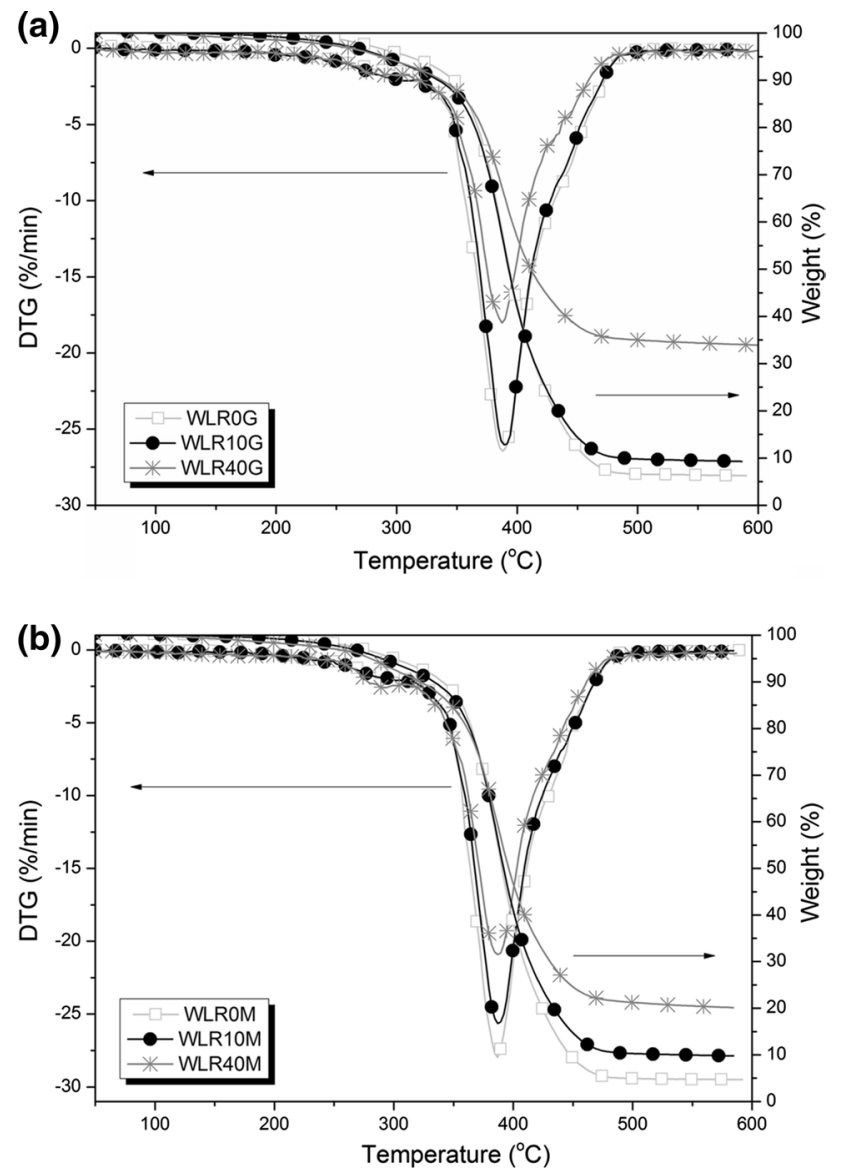

Fig. 3 Differential thermogravimetric (DTG) and thermogravimetric (TGA) curves of the reference samples and those containing 10 and $40 \mathrm{phr}$ lignin with the use of: a glycerolysate; and b naphthenic oil as plasticizer the thermogravimetric (TGA) and differential thermogravimetric (DTG) graphs, which are shown in Fig. 3.

Both figures disclosed one step of thermal decomposition for all samples (Fig. 3a, b). That is initiated by thermal tearing $\mathrm{C}-\mathrm{C}$ bonds from NR macromolecular chains [3]. The highest rate of weight loss revealed the samples with maximum lignin content. In the case of reference samples (Fig. 3a, b), the rate of weight loss of the glycerolysatebased specimens revealed slightly greater value than the reference sample with the use of naphthenic oil. The analysis indicates that the content of the glycerolysate in the kraft lignin-natural rubber composites is affected by the decrease in the rate of weight loss in comparison to naphthenic oil influence [39].

In all samples, the thermal degradation behavior is similar in the context of weight loss procedure to the temperature at $\sim 400{ }^{\circ} \mathrm{C}$. After this point, the thermal degradation of each sample revealed different trends. Reference samples after testing exhibited the highest weight loss, whereas minimum weight loss revealed specimens with 40 phr lignin content with the use of glycerolysate as a plasticizer.

The temperatures of the thermal degradation characteristics of the obtained bio-based materials and pure components, such as glycerolysate, naphthenic oil, natural rubber, and kraft lignin, are summarized in Table 2. The temperature of the highest rate of weight loss for each sample is at the temperature of $\sim 388{ }^{\circ} \mathrm{C}$. The residual weight after TGA analysis (for $600{ }^{\circ} \mathrm{C}$ ) results not only from the presence of the highest lignin content but also glycerolysate, which is the product of polyurethanes chemical decomposition.
Table 2 Thermal degradation characteristics of the ligninrubber composites and used glycerolysate, naphthenic oil, natural rubber, and kraft lignin

\begin{tabular}{llllll}
\hline Samples & \multicolumn{7}{l}{ Thermal degradation characteristic $\left({ }^{\circ} \mathrm{C}\right)$} \\
\cline { 2 - 6 } & $T_{5 \%}$ & $T_{50 \%}$ & $T_{80 \%}$ & $T_{\text {max }}($ first stage/second stage $)$ & Residue at $600{ }^{\circ} \mathrm{C}(\%)$ \\
\hline Plasticizer & \multicolumn{2}{l}{ Glycerolysate } & & & \\
WLR0G & 309 & 392 & 430 & 388 & 6 \\
WLR10G & 290 & 394 & 435 & 389 & 9 \\
WLR40G & 286 & 408 & - & 388 & 33 \\
Plasticizer & Naphthenic oil & & & 5 \\
WLR0M & 294 & 393 & 429 & 388 & 9 \\
WLR10M & 290 & 393 & 433 & 387 & 20 \\
WLR40M & 279 & 396 & 584 & 387 & 8 \\
Glycerolysate & 278 & 347 & 430 & $310 / 410$ & 0 \\
Naphthenic oil & 293 & 367 & 390 & $370 / 388$ & 59 \\
Kraft lignin & 275 & - & - & 294 & 0 \\
Natural rubber & 343 & 391 & 413 & 391 & 5 \\
\hline
\end{tabular}

$T_{5 \%}$, temperature of $5 \%$ weight loss; $T_{50 \%}$, temperature of $50 \%$ weight loss; $T_{80 \%}$, temperature of $80 \%$ weight loss; $T_{\max }$, temperature of maximum rate of weight loss. Residue at $600{ }^{\circ} \mathrm{C}(\%)$ 


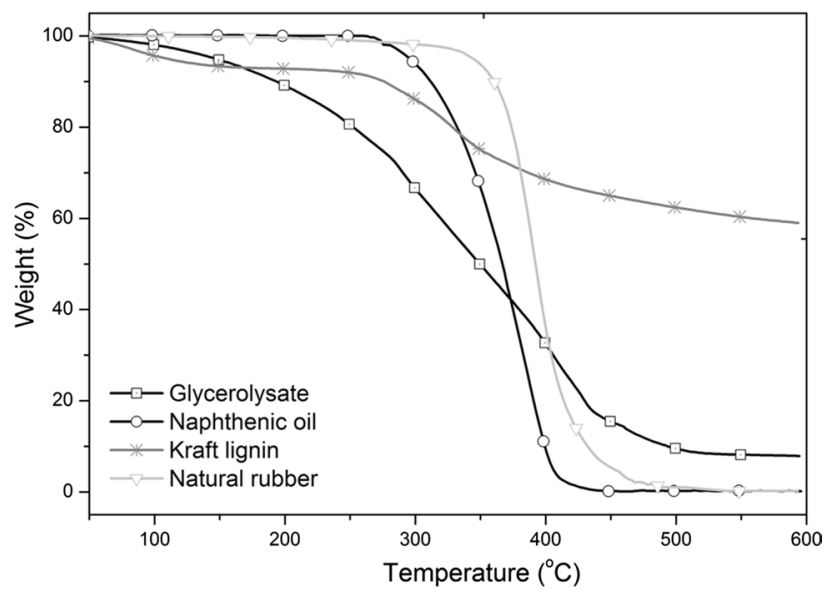

Fig. 4 Thermogravimetric curves of the pure glycerolysate, naphthenic oil, natural rubber, and kraft lignin used for preparation of the composites

Figure 4 proved that glycerolysate, at the end of the test, created more residues than naphthenic oil. The glycerolysate content did not negatively affect the residues in the composite with $10 \mathrm{phr}$ of lignin. In the case of composites with $40 \mathrm{phr}$ of lignin, the impact of the glycerolysate on the residues after the test was greater. Despite that the glycerolysate degrades faster at a lower temperature in comparison with naphthenic oil, the applied amount of plasticizer did not negatively affect the thermal stability of the prepared composites (Fig. 4). The kraft lignin curve shows two steps of weight loss which indicate moisture content in lignin specimen during the test. Moreover, the lignin curve indicates the highest content of ashes. Residues formed after the kraft lignin test contained organic and inorganic contaminants. The content of the impurities lowered the filler quality and thereby the lignin softening effect in the composites. Furthermore, impurities which may cause heat transfer problem in the whole volume of the composite samples can consequently hinder their thermal processing $[8,40]$.

\section{Dynamic mechanical analysis (DMA)}

The DMA analysis was used to characterize the dynamic mechanical behavior of the prepared bio-based composites. Variation of the storage modulus (E') versus temperature and variation of tangent delta $(\tan \delta)$ versus temperature are shown in Fig. 5a (glycerolysate-based composites) and b (naphthenic oil-based composites). It was observed that the kraft lignin and type of the used plasticizer strongly influenced the thermomechanical properties of the prepared natural rubber composites. All the curves indicated distinct single-peaks. Addition of the kraft lignin in the natural rubber matrix with the use of glycerolysate as plasticizing (a)

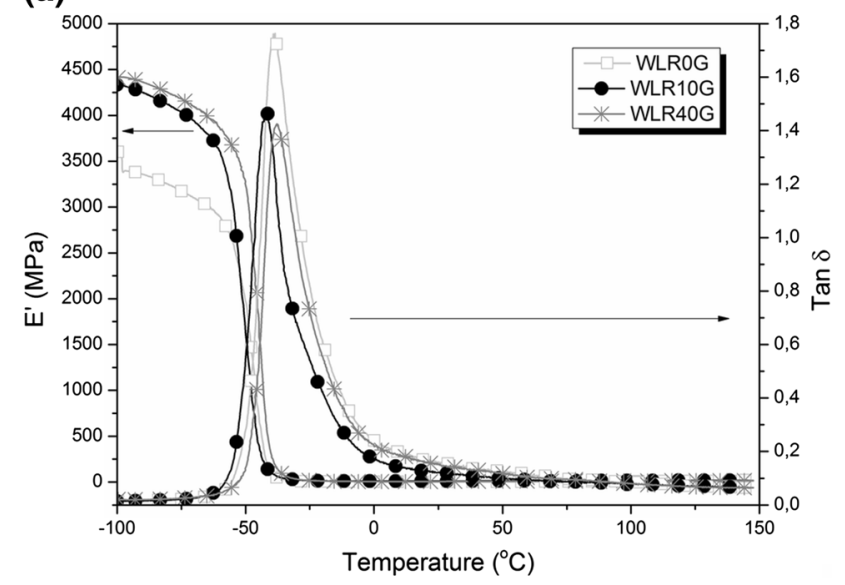

(b)

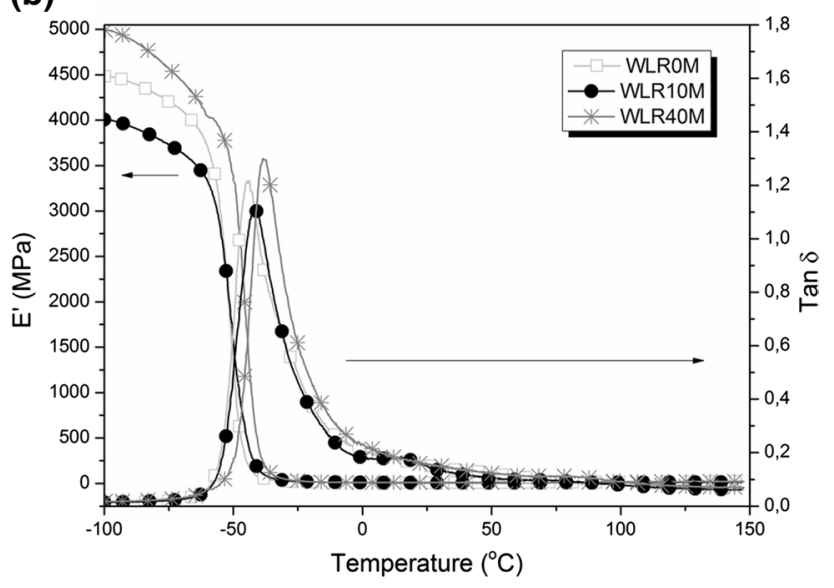

Fig. 5 Storage modulus $\mathrm{E}^{\prime}(\mathrm{MPa})$ and $\tan \delta$ of lignin-rubber composites prepared with the use of: a glycerolysate; and $\mathbf{b}$ naphthenic oil as plasticizer

agent increased the storage modulus and decreased the $\tan \delta$ compared to the reference specimen (Fig. 5a). For naphthenic oil-based composites, the decreasing in the storage modulus and value of $\tan \delta$ was observed only for WLR10M sample (Fig. 5b). According to the literature $[4,41,42]$, the storage modulus $\left(E^{\prime}\right)$ is clearly correlated with the degree of elasticity, which is also proportional to the crosslink density. Based on the results of the dynamic mechanical analysis of the reference samples, it can be described that the glycerolysate led to decreasing the stiffness and increasing the ability to the damping capacity of the natural rubber matrix compared to the naphthenic oilbased reference specimen. The storage modulus values changed to $\sim 4500$ and $\sim 3600$ MPa for naphthenic oil- and glycerolysate-based reference samples, respectively. For the prepared natural rubber composites, the lower stiffness of $4000 \mathrm{MPa}$ was revealed for sample WLR10 M. The values of the storage modulus of all the specimens strongly decreased in the temperature range between -60 
and $-20{ }^{\circ} \mathrm{C}$ (Fig. 5a, b). Geethamma et al. [42] suggested that this phenomenon is related to the glass transition temperature of the natural rubber matrix. The midpoint of the decreasing curve part indicates the approximate glass transition temperature [25], which is closely associated with the relaxation of the natural rubber chains. The cooperative motion of macromolecules induced the dissipation of energy at the temperature of the maximum tangent delta. After $-25{ }^{\circ} \mathrm{C}$, the curve characteristics are related to the remaining crystalline regions melting in the macromolecule chains from natural rubber matrix.

According Fig. 5a and b, the samples with naphthenic oil as plasticizer disclosed that the $\alpha$-transition temperature increased with increasing lignin content. The addition of $10 \mathrm{phr}$ of lignin in the glycerolysate-based composite caused the $\alpha$-transition temperature to decrease from $\sim-40{ }^{\circ} \mathrm{C}$ for reference sample to $\sim-42{ }^{\circ} \mathrm{C}$ for WLR10G. For specimen with $40 \mathrm{phr}$ of lignin content and glycerolysate as plasticizer, this temperature is similar to the reference sample. The lowest value $\left(-44^{\circ} \mathrm{C}\right)$ was determined for the naphthenic oil-based reference sample. The value of $\tan \delta$ is correlated with the degree of crosslinking density of the macromolecular chains [43]. The decreasing trend with growing filler content in the composites suggested the decline in the crosslinking in the prepared materials. This fact can be explained by the kraft-lignin agglomerates formation. These agglomerates are formed when the filler is not well dispersed in the rubber matrix and thereby inaccurately solvated by macromolecule chains. Consequently, the chain mobility is restricted and the reinforcement effect cannot be provided in the composites.

The highest tangent delta peak was observed for the reference sample with the use of glycerolysate as a plasticizer. The values of $\tan \delta$ of all investigated samples were between 1.1 and 1.4 for naphthenic oil-based composites and between 1.4 and 1.8 for glycerolysate-based materials. This indicates that synthesized materials have obtained good damping capacity; nonetheless, with increasing filler content this capacity is slightly declined (except for WLR10M sample). The decrease in 'peaks intensity results from the reduction in macromolecular movement due to the formation of lignin particle agglomerates [39]. It is noteworthy that WLR40M sample indicates the growing intensity of the $\tan \delta$ peak, suggesting improvement in composite damping capacity. This can be explained by the specific distribution of filler agglomerates (in the highest amount from all composites). These agglomerates are bigger than those in the other composites and the surrounding natural rubber macromolecular chain movement is improved. Consequently, there is more energy loss, indicating better damping capacity.

\section{Mechanical properties}

The effect of lignin content and used plasticizer on the tensile properties (i.e., tensile modulus at 100 and $300 \%$ elongation, tensile strength, elongation-at-break, and permanent elongation after the break) of the kraft lignin-natural rubber composites is shown in Table 3 .

The results of the tensile modulus at 100 and $300 \%$ elongation exhibited increases in all the composites except WLR10M. For this composite, the tensile modulus at $300 \%$ elongation disclosed a lower value than other samples. The lowest modules were obtained for the reference specimens without lignin content. It is well-known that the tensile modulus is correlated with the sample elasticity. Moreover, the filler hardness affected the tensile modulus values. The addition of lignin caused to reduce the elasticity due to the high hardness of the filler, which hindered the material deformation. Datta and co-workers [31] indicated the similar results.

It was found that with increasing amounts of lignin all the samples revealed a drop in tensile strength. The same trend was also disclosed in the case of elongation-at-break. The decrease in the tensile properties can result from the fillerdepend factors. Partially dispersed or irregularly shaped filler particles cause stress concentration which results in faster material breakings. A different behavior was observed for the composite containing $10 \mathrm{phr}$ of lignin using glycerolysate as plasticizer. The tensile strength was similar in both

Table 3 The effect of the used plasticizer on the tensile properties of the kraft lignin-natural rubber composites containing different lignin contents

\begin{tabular}{llllll}
\hline Composite & TM100 $(\mathrm{MPa})$ & TM300 $(\mathrm{MPa})$ & TS $(\mathrm{MPa})$ & Elongation- at-break $(\%)$ & Permanent elongation after break $(\%)$ \\
\hline WLR0G & $0.81 \pm 0.04$ & $1.92 \pm 0.03$ & $16.25 \pm 1.1$ & $717 \pm 12$ & $18 \pm 1$ \\
WLR10G & $0.92 \pm 0.03$ & $1.94 \pm 0.03$ & $15.17 \pm 1.1$ & $672 \pm 10$ & $15 \pm 2$ \\
WLR40G & $1.07 \pm 0.04$ & $2.06 \pm 0.03$ & $10.61 \pm 0.2$ & $630 \pm 6$ & $18 \pm 2$ \\
WLR0M & $0.76 \pm 0.05$ & $1.97 \pm 0.04$ & $16.97 \pm 1.9$ & $698 \pm 27$ & $18 \pm 2$ \\
WLR10M & $0.86 \pm 0.05$ & $1.78 \pm 0.03$ & $13.84 \pm 1.1$ & $725 \pm 20$ & $22 \pm 2$ \\
WLR40M & $1.01 \pm 0.03$ & $1.99 \pm 0.03$ & $10.55 \pm 0.4$ & $645 \pm 33$ & 17 \\
\hline
\end{tabular}

TM100 and TM300 are the tensile modulus of 100 and 300\% elongation (MPa), respectively, and TS denotes the tensile strength (MPa) 
WLR10G composite and reference sample; however, the WLR10G composite revealed a lower elongation. This may be a proof in the absence of a lignin reinforcing effect on the composites. The tensile strength depends on the crosslink density and on the energy dissipation in the composites [44]. With the increase in the amount of filler, the crosslink density decreases and makes the process of crosslinking difficult. Lignin contains the $\mathrm{OH}$ group which can adsorb rubber additives. What is more, lignin could hinder vulcanization of rubber for its radical scavenging effect due to the lignin phenol structure. Thus, the addition of lignin could lower the crosslinking density of rubber composite.

The impact of lignin content on the elongation-at-break revealed the decreasing trend with the growing amount of lignin for the glycerolysate composites. The dependence of elongation-at-break on the lignin content in the samples containing naphthenic oil as plasticizer is not clear. The highest elongation-at-break was observed for the bio-composites with $10 \mathrm{phr}$ of lignin, and the smallest elongation was observed for the samples with $40 \mathrm{phr}$ of lignin, which can be explained by the occurrence of lignin agglomerations in the composite microstructure.

The highest permanent elongation after the break was revealed in the samples with $40 \mathrm{phr}$ of lignin (plasticizer type-independent samples) and in the reference samples. The lowest values were observed in the case of specimens with $10 \mathrm{phr}$ of lignin using glycerolysate as plasticizer, which confirm the highest possibility to return to the state before the test.

Table 4 shows the results of hardness, resilience, density, and abrasiveness tests of the prepared kraft lignin-natural rubber composites. The increasing amount of lignin causes the growing trend in the hardness value of the composites (Table 4). Higher hardness was disclosed in the specimens with the use of glycerolysate as plasticizer. However, in the case of reference samples, higher hardness was revealed in the naphthenic oil-bases composites. Hardness is closely connected with the crosslink density [27]. With the increasing amount of lignin in the composites, the hardness decreased due to the molecular chain mobility hindered by the filler agglomerates and consequently the reduction of crosslink density. This resulted in reduced elasticity of the samples which led to more rigid composites.
Rebound resilience tests showed that the glycerolysatebased composites disclosed the decrease in its value with increasing amount of lignin. In the case of bio-based composites obtained with the use of naphthenic oil, there was first an increase in rebound resilience for the sample with $10 \mathrm{phr}$ of lignin and then decreased for the sample with $40 \mathrm{phr}$ of lignin. These results are attributed to the decrease in the mobility of rubber chains with the growing amount of lignin. The formation of agglomerates resulted in harder and stiffer composites, which can assimilate the energy easier. The same results are presented in literature [24, 27].

Composites' density is strictly correlated with the lignin content; thus the highest and lowest values were, respectively, obtained for the samples with $40 \mathrm{phr}$ of lignin content and the reference specimens.

Increasing mass loss during the abrasion test is associated with the increasing amount of lignin in all the prepared materials, resulting in the formation of big-size agglomerates. The lowest abrasiveness was revealed by the reference samples. Among all prepared kraft lignin-natural rubber composites, the composites with $10 \mathrm{phr}$ of lignin, using glycerolysate as plasticizer, showed the greatest value of abrasion resistance similar to the reference samples.

\section{Equilibrium swelling characteristics}

The effect of lignin content on the composite network structures was investigated by the equilibrium swelling measurements (Table 5). By the obtained results the determination of the swelling ratio, volume fraction of rubber network, the molecular weight of the polymer between the crosslink points and the crosslink density was made possible.

The bio-based composites containing $10 \mathrm{phr}$ of lignin possess the highest swelling ratio index among all the specimens. The swelling ratio index is determined as the amount of solvent absorbed by the samples. In the case of the highest amount of lignin, the swelling ratio is characterized by the lowest values. The swelling ratio is mainly related to the crosslink density; therefore, the composites with the highest lignin content showed the lowest crosslink density and the maximum interaction between the rubber chain and filler particles [24,
Table 4 Results of hardness, resilience, density, and abrasiveness tests of the composites studied

\begin{tabular}{lllll}
\hline Composite & Hardness $\left({ }^{\circ} \mathrm{Sh} \mathrm{A}\right)$ & Resilince $(\%)$ & Density $\left(\mathrm{g} / \mathrm{cm}^{3}\right)$ & Abrasivness $\left(\mathrm{cm}^{3}\right)$ \\
\hline WLR0G & $43.6 \pm 0.3$ & $58.7 \pm 2.0$ & $0.9724 \pm 0.0003$ & $0.0899 \pm 0.008$ \\
WLR10G & $47.3 \pm 0.4$ & $57.9 \pm 1.2$ & $0.9966 \pm 0.0002$ & $0.0988 \pm 0.021$ \\
WLR40G & $54.2 \pm 0.2$ & $51.1 \pm 0.7$ & $1.0548 \pm 0.0009$ & $0.2397 \pm 0.414$ \\
WLR0M & $44.7 \pm 0.3$ & $57.2 \pm 2.3$ & $0.9673 \pm 0.0006$ & $0.0806 \pm 0.008$ \\
WLR10M & $47.0 \pm 0.3$ & $60.1 \pm 1.6$ & $0.9923 \pm 0.0009$ & $0.1174 \pm 0.015$ \\
WLR40M & $52.8 \pm 0.3$ & $49.2 \pm 1.7$ & $1.0543 \pm 0.0008$ & $0.2292 \pm 0.039$ \\
\hline
\end{tabular}


Table 5 Results of the swelling measurements of the ligninrubber composites

\begin{tabular}{lllll}
\hline Composite & SR $(\%)$ & $V_{\text {fr }}$ & $M_{\mathrm{C}}(\mathrm{g} / \mathrm{mol})$ & $\begin{array}{l}\nu \times 10^{-3} \\
\left(\mathrm{~mol} / \mathrm{cm}^{3}\right)\end{array}$ \\
\hline WLR0G & $272.7 \pm 3.0$ & $0.2492 \pm 0.0029$ & $182.7 \pm 2.1$ & $5.32 \pm 0.06$ \\
WLR10G & $280.4 \pm 1.0$ & $0.2286 \pm 0.0007$ & $203.6 \pm 0.6$ & $4.89 \pm 0.01$ \\
WLR40G & $239.5 \pm 1.4$ & $0.2170 \pm 0.0012$ & $226.5 \pm 1.2$ & $4.66 \pm 0.02$ \\
WLR0M & $256.7 \pm 1.3$ & $0.2584 \pm 0.0009$ & $175.3 \pm 0.6$ & $5.52 \pm 0.02$ \\
WLR10M & $260.5 \pm 3.7$ & $0.2394 \pm 0.0025$ & $193.9 \pm 2.0$ & $5.12 \pm 0.05$ \\
WLR40M & $236.7 \pm 6.4$ & $0.2165 \pm 0,0140$ & $227.3 \pm 13.9$ & $4.65 \pm 0.28$ \\
\hline
\end{tabular}

SR, swelling ratio; $V_{\mathrm{fr}}$, volume fraction of rubber; $M_{\mathrm{c}}$, molecular weight between the crosslink points; $v$, crosslink density
45]. The results of the swelling measurements can be explained by the agglomerate formation. In the composites with the highest amount of lignin, the biggest agglomerates caused to form the polysulfidic crosslinks between the natural rubber chains with a lower possibility of formation. Meanwhile, the disulfidic and monosulfdic crosslinks remained constant [46]. The filler particles masked some of the sites on the matrix macromolecules, which hindered the crosslinking reaction and led to the reduction of the network density. The distance between the network points was increased with decreasing the crosslink density and amount of agglomerates. With the growth of the distance between the networks, the polymer chain revealed higher tangling level. The results associated with the molecular weight between the crosslink points confirmed the increased complexity of natural rubber macromolecules between the network points.

The decreasing amount of polysulfidic crosslinks influenced the mechanical performance reduction [47]. From SEM analysis it can be observed that in the biobased composites with $10 \mathrm{phr}$ of lignin, the filler particles are better distributed in the polymer matrix, than the materials with $40 \mathrm{phr}$ of lignin. The mechanical properties and the thermal analysis also confirmed better properties of the samples with addition of $10 \mathrm{phr}$ of lignin.

Figure 6 shows the time of solvent uptake by the composites. All the samples achieved maximum extent of swelling at the same time. Only in the case of the composite with $40 \mathrm{phr}$ of lignin, prepared using glycerolysate as plasticizer, the prolonged time of mass change was observed. The lowest mass change was observed for the reference sample with the use of naphthenic oil as plasticizer. Nevertheless, the highest solvent uptake was revealed for the glycerolysate-based composites without and with $40 \mathrm{phr}$ of lignin content. For the glycerolysatebased composites (WLR10G), in a medium amount of lignin, the mass change radically decreased to the mass change obtained for the naphthenic oil-based composites. This measurement verified that the optimum lignin

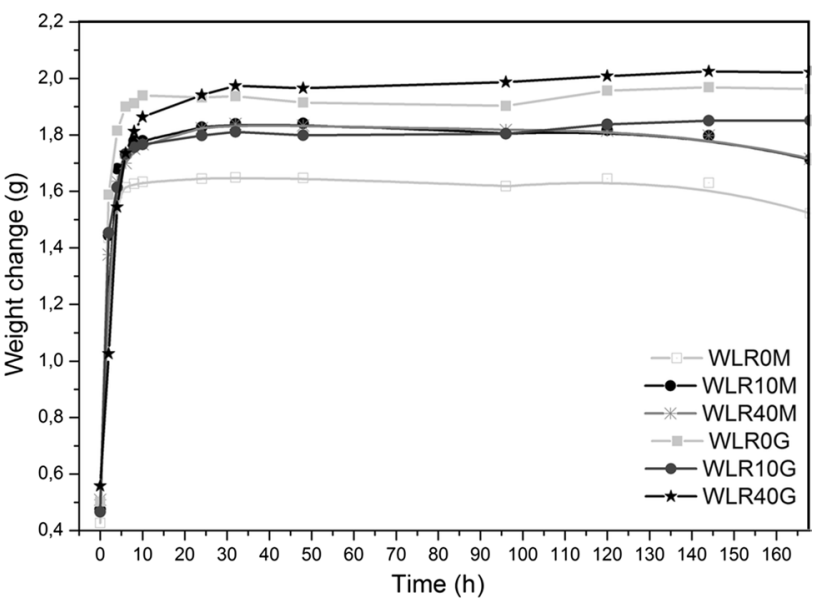

Fig. 6 Weight change during the swelling measurements for ligninrubber composites using the two individual plasticizers

content for the glycerolysate-based composites was 10 phr because their solvent resistance was similar to that of the naphthenic oil-based composites.

\section{Conclusion}

The growing ecological trend in the chemistry, chemical technology, and materials engineering has caused increasing interest in the use of the chemical recycling product and biorenewables in the polymer industries. The results of our studies proved the opportunity to utilize a semiproduct of the chemical recycling of polyurethanes (i.e., glycerolysate) as a novel plasticizer in the natural rubber composites. The performed studies indicated comparable or even better properties of the glycerolysate-based composites in comparison with the composites based on the commonly used naphthenic oil-based plasticizers. Moreover, a kraft lignin by-product of pulp and paper industry (biorenewable) was added as filler in various amounts. The composite obtained with the use of glycerolysate as 
plasticizer, with the optimal amount of the lignin (i.e., $10 \mathrm{phr}$ ), showed the best properties, which would be promising in exceptional opportunities in many applications. Thermal stability of the glycerolysate-based composites confirmed by TGA was the same as that of the commonly used naphthenic oil-based composites. The replacement of naphthenic oil by glycerolysate in the same concentration did not cause dramatic changes in the natural rubber composite's characteristic. The $\alpha$-transition temperature of the glycerolysate-based materials was the same compared to that of the naphthenic oil-based composites $\left(-42{ }^{\circ} \mathrm{C}\right.$ for the composites with $10 \mathrm{phr}$ lignin content and $-38^{\circ} \mathrm{C}$ for the composites with $40 \mathrm{phr}$ lignin content). Scanning electron microscopy analysis did not indicate any differences between the composites with the same lignin amount. SEM micrographs showed similarity in the agglomerates' formation in both plasticizers. In the case of mechanical properties, the composite with optimal lignin content (WLR10G) showed the lowest abrasiveness among all the composites. The same material (WLR10G) revealed a lower crosslink density than the naphthenic oil-based countertype. This analysis confirmed the higher tensile strength and lower elongation-at-break for the glycerolysate-based composites with $10 \mathrm{phr}$ lignin content compared to naphthenic oil-based equivalent. The obtainment of lignin/natural rubber composites as bio-based materials has an environmentfriendly character as well as being beneficial from the economic point of view, due to the low cost of ingredients and materials used in production and easy access to the components needed in this study.

Acknowledgements The authors gratefully acknowledge the MeadWestvaco Corporation, Specialty Chemical Division, South Carolina, USA, for supplying the kraft lignin powder samples used in this study.

\section{Compliance with ethical standards}

Conflict of interest The authors declare that they have no conflict of interest.

Open Access This article is distributed under the terms of the Creative Commons Attribution 4.0 International License (http://creativecommons.org/licenses/by/4.0/), which permits unrestricted use, distribution, and reproduction in any medium, provided you give appropriate credit to the original author(s) and the source, provide a link to the Creative Commons license, and indicate if changes were made.

\section{References}

1. Haghdan S, Renneckar S, Smith GD (2016) Sources of lignin. In: Lignin polymer composites. Elsevier, Amsterdam

2. Laurichesse S, Avérous L (2014) Chemical modification of lignins: towards biobased polymers. Prog Polym Sci 39:1266-1290
3. Jiang C, He H, Jiang H, Ma L, Jia DM (2013) Nano-lignin filled natural rubber composites: preparation and characterization. Express Polym Lett 5:480-493

4. Yu P, He H, Jiang C, Wang D, Jia Y, Zhou L, Jia DM (2015) Reinforcing styrene butadiene rubber with lignin-novolac epoxy resin networks. Express Polym Lett 9:36-48

5. Bahl K, Swanson N, Pugh C, Jana SC (2014) Polybutadiene$g$-polypentafluorostyrene as a coupling agent for lignin-filled rubber compounds. Polymer 55:6754-6763

6. Kosikova B, Gregorova A, Osvald A, Krajcovicova J (2007) Role of lignin filler in stabilization of natural rubber-based composites. J Appl Polym Sci 103:1226-1231

7. Gregorová A, Košíková B, Moravčík R (2006) Stabilization effect of lignin in natural rubber. Polym Degrad Stab 91:229-233

8. Kadla JF, Kubo S, Venditti RA, Gilbert RD, Compere AL, Griffith W (2002) Lignin-based carbon fibers for composite fiber applications. Carbon 40:2913-2920

9. Abdelmouleh M, Boufi S, Belgacem MN, Dufresne A (2007) Short natural-fibre reinforced polyethylene and natural rubber composites: effect of silane coupling agents and fibres loading. Compos Sci Technol 67:1627-1639

10. Kopczyńska P, Datta J (2016) Single-phase product obtained via crude glycerine depolymerisation of polyurethane elastomer: structure characterisation and rheological behaviour. Polym Int 65:946-954

11. Yang W, Dong Q, Liu S, Xie H, Liu L, Li J (2012) Recycling and disposal methods for polyurethane foam wastes. Procedia Environ Sci 16:167-175

12. Zia KM, Bhatti HN, Bhatti IA (2007) Methods for polyurethane and polyurethane composites, recycling and recovery: a review. React Funct Polym 67:675-692

13. Simón D, de Lucas A, Rodríguez JF, Borreguero AM (2016) Glycolysis of high resilience flexible polyurethane foams containing polyurethane dispersion polyol. Polym Degrad Stab 133:119-130

14. Datta J, Pasternak S (2005) Oligourethane glycols obtained in glycolysis of polyurethane foam as semi-finiszed products for cast urethane elastomers preparation. Polim J 50:352-357

15. Datta J (2010) Synthesis and investigation of glycolysates and obtained polyurethane elastomers. J Elastomers Plast 42:117-127

16. Datta J, Rohn M (2007) Glikoliza odpadów poliuretanowych. Polim J 52:625-710

17. Fukaya T, Watando H, Fujieda S, Saya S, Thai CM, Yamamoto M (2006) Reheating decomposition process as chemical recycling for rigid polyurethane foam. Polym Degrad Stab 91:2549-2553

18. Vieira MGA, Da Silva MA, Dos Santos LO, Beppu MM (2011) Natural-based plasticizers and biopolymer films: a review. Eur Polym J 47:254-263

19. Alexander M, Thachil ET (2006) A comparative study of cardanol and aromatic oil as plasticizers for carbon-blackfilled natural rubber. J Appl Polym Sci 102:4835-4841

20. Mohapatra S, Nando GB (2014) Cardanol: a green substitute for aromatic oil as a plasticizer in natural rubber. Rsc Adv 4:15406-15418

21. Da Silva AM, Adeodato Vieira MG, Gomes Maumoto AC, Beppu MM (2011) Polyvinylchloride (PVC) and natural rubber films plasticized with a natural polymeric plasticizer obtained through polyesterification of rice fatty acid. Polym Test 30:478-484

22. Datta J, Parcheta P, Surówka J (2017) Softwood-lignin/natural rubber composites containing novel plasticizing agent: preparation and characterization. Ind Crop Prod 95:675-685

23. Datta J, Głowińska E (2011) Influence of cellulose on mechanical and termomechanical properties of elastomers obtained from mixtures containing natural rubber. Polimery 61:823-827 
24. Jacob M, Thomas S, Varughese KT (2004) Mechanical properties of sisal/oil palm hybrid fiber reinforced natural rubber composites. Compos Sci Technol 64:955-965

25. Chonkaew W, Minghvanish W, Kungliean U, Rochanawipart N, Brostow W (2010) Vulcanization characteristics and dynamic mechanical behavior of natural rubber reinforced with silane modified silica. J Nanosci Nanotechnol 10:2018-2024

26. Datta J, Głowińska E (2014) Effect of hydroxylated soybean oil and bio-based propanediol on the structure and thermal properties of synthesized bio-polyurethanes. Ind Crops Prod 61:84-91

27. Stelescu M, Manaila E, Craciun G, Dumitrascu M (2014) New green polymeric composites based on hemp and natural rubber processed by electron beam irradiation. Sci World J 2014:1-13

28. Yaragalla S, Meera AP, Kalarikkal N, Thomas S (2015) Chemistry associated with natural rubber-graphene nanocomposites and its effect on physical and structural properties. Ind Crop Prod 74:792-802

29. Riyajan SA (2015) Robust and biodegradable polymer of cassava starch and modified natural rubber. Carbohydr Polym 134:267-277

30. Kubačková J, Ferenc J, Hudec I, Šutý Š, Jablonský M, Annus J, Pret'o J (2013) Antioxidant properties of lignin in rubber blends. Elastomery J 17:21-27

31. Datta J, Kosiorek P, Włoch M (2016) Effect of high loading of titanium dioxide particles on the morphology, mechanical and thermo-mechanical properties of the natural rubber-based composites. Iran Polym J 25:1021-1035

32. Joseph S, Appukuttan SP, Kenny JM, Puglia D, Thomas S, Joseph K (2010) Dynamic mechanical properties of oil palm microfibril-reinforced natural rubber composites. J Appl Polym Sci 117:1298-1308

33. Datta J, Włoch M (2015) Morphology and properties of recycled polyethylene/ground tyre rubber/thermoplastic poli(ester-urethane) blands. Macromol Res 23:1-10

34. Lin Y, Chen Y, Zeng Z, Zhu J, Wei Y, Li F, Liu L (2015) Effect of $\mathrm{ZnO}$ nanoparticles doped graphene on static and dynamic mechanical properties of natural rubber composites. Compos Part A 70:35-44

35. Pillai KV, Renneckar S (2009) Cation- $\pi$ interactions as a mechanism in technical lignin adsorption to cationic surfaces. Biomacromol 10:798-804

36. Yang D, Rochette J, Sacher E (2005) Spectroscopic evidence for $\pi-\pi$ interaction between poly (diallyl dimethylammonium) chloride and multiwalled carbon nanotubes. J Phys Chem B 109:4481-4484

37. Phakkeeree T, Ikeda Y, Yokohama H, Phinyocheep P, Kitano R, Kato A (2016) Network-like structure of lignin in natural rubber matrix to form high performance elastomeric bio-composite. J Fiber Sci Technol 72:160-165

38. Jiang C, He H, Yao X, Yu P, Zhou L, Jia D (2015) In situ dispersion and compatibilization of lignin/epoxidized natural rubber composites: reactivity, morphology and property. J Appl Polym Sci 132:1-10

39. Kargarzadeh H, Sheltami RM, Ahmad I, Abdullah I, Dufresne A (2015) Cellulose nanocrystal reinforced liquid natural rubber toughened unsaturated polyester: effects of filler content and surface treatment on its morphological, thermal, mechanical, and viscoelastic properties. Polymer 71:51-59

40. Hu TQ (2002) Chemical modification, properties and usage of lignin. Springer, New York

41. Cao X, Xu C, Wang Y, Liu Y, Liu Y, Chen Y (2013) New nanocomposite materials reinforced with cellulose nanocrystals in nitrile rubber. Polym Test 32:819-826

42. Geethamma VG, Kalaprasad G, Groeninckx G, Thomas S (2005) Dynamic mechanical behavior of short coir fiber reinforced natural rubber composites. Compos Part A Appl Sci Manuf 36:1499-1506

43. Głowińska E, Datta J, Parcheta P (2017) Effect of sisal fiber filler on thermal properties of bio-based polyurethane composites. $\mathbf{J}$ Therm Anal Calorim. doi:10.1007/s10973-017-6293-5

44. Bras J, Hassan ML, Bruzesse C, Hassan EA, El-Wakil NA, Dufresne A (2010) Mechanical, barrier, and biodegradability properties of bagasse cellulose whiskers reinforced natural rubber nanocomposites. Ind Crops Prod 32:627-633

45. Park SJ, Cho KS (2003) Filler-elastomer interactions: influence of silane coupling agent on crosslink density and thermal stability of silica/rubber composites. J Colloid Interface Sci 267:86-91

46. Kakroodi AR, Sain M (2016) Lignin-reinforced rubber composites. In: Lignin polymer composites. Elsevier, Toronto

47. Stelescu MD, Georgescu M, Manaila E (2010) Aspects regarding crosslinking of a natural rubber blend. In: Proceedings of the 3rd international conference on advanced materials and systems. $p$ 313-318 